\title{
A necessidade um olhar biopsicosociocultural na ciência da Nutrição
}

\section{The need for a "biopsychosocialcultural" perspective at Nutrition Science}

Marle Alvarenga ${ }^{1}$

A Nutrição, classicamente classificada como uma disciplina da área das biológicas, infelizmente tem focado muito apenas os nutrientes, sendo caracterizada hoje até pelo nutricionismo: foco tão grande no nutriente e energia que faz as pessoas esquecerem que comem comida. Concordamos com alguns pesquisadores que afirmam que a Nutrição pode ser quase classificada como "uma racionalidade científica do comer".

A interdisciplinaridade na área da alimentação é fundamental, e a Nutrição como ciência precisa aprender muito com historiadores, antropólogos, sociólogos e outros pesquisadores das ciências humanas, para resgatar o foco no alimento - que vem antes do nutriente; e também o foco no ser humano comedor e consumidor - que vem antes de um processo fisiológico e metabólico de assimilação de nutrientes.

Alguns pesquisadores da área da Nutrição têm se debruçado sobre o tema alimento e seus arredores socioculturais e psicológicos, mas há muito a ampliar nesse sentido, e a interdisciplinaridade é, portanto, fundamental.

Esta necessidade se evidencia também pelo fato de que nunca se falou tanto de Nutrição e o acesso às informações sobre o tema nunca foi tão amplo (mesmo havendo desinformação e controvérsias), mas as pessoas não estão mais saudáveis: os índices de obesidade e transtornos alimentares e doenças crônicas não transmissíveis atestam isto. Mais do que nunca é preciso entender os múltiplos fatores envolvidos nas decisões sobre o que comer, e apenas parâmetros nutricionais numéricos de necessidades e recomendações não vão responder às demandas da atualidade.

Palavras-chave: nutrição; interdisciplinaridade; alimentação; nutricionismo.

Keywords: nutrition; interdisciplinarity; food; nutritionism.

1 Mestre e doutora em Nutrição Humana Aplicada pela Universidade de São Paulo, concluiu o pós-doutorado no Departamento de Nutrição da Faculdade de Saúde Pública (FSP) da USP, com um período como "short-term scholar" na Pennsylvania University. É professora visitante do Departamento de Nutrição da FSP-USP e credenciada como orientadora no programa de pós-graduação em Nutrição em Saúde Pública da mesma instituição. No Il Simpósio Internacional de Pesquisa em Alimentação, participou da mesa-redonda "Interdisciplinaridade na pesquisa em alimentação". 